\title{
Nuevos roles de los gobiernos locales en la implementación de políticas públicas. Gobernabilidad territorial y competitividad global
}

Edgar Varela. Universidad del Valle, Santiago de Cali, Colombia.

RESUMEN | Se analiza la emergencia de un nuevo paradigma que determina roles diferenciados y contrapuestos a los esquemas clásicos vigentes en los gobiernos locales, particularmente en las regiones metropolitanas, desarrollados como resultado de tendencias globales. Tales cambios, provenientes de la economía, la mercantilización de los bienes públicos y la liberalización e integración de los mercados, afectan los diseños institucionales tradicionales, que les otorgan competencias delimitadas y subordinadas a los gobiernos locales en el marco de un modelo soberanista centrado en el Estado-Nación. Con la globalización, este esquema ha cambiado y hoy los gobiernos locales asumen en las grandes ciudades nuevas competencias, las cuales corresponden a la emergencia de nodos metropolitanos que se articulan con los mercados globales y con dinámicas de reconfiguración de flujos económicos, políticos, sociales y demográficos. Este proceso ocurre en términos de redes de ciudades y de integración de regiones con esquemas asimétricos de concentración de recursos y poder, modificando el mapa del desarrollo territorial.

PALABRAS CLAVE | gobiernos locales, globalización, políticas públicas.

ABSTRACT | This paper examines the emergence of a new paradigm that determines differentiated and conflicting roles in the classic schemes regarding local government, particularly in metropolitan areas, in a process that has emerged as a result of global trends. With roots in the economy, the mercantilization of public goods, and the liberalization and integration of markets, such trends affect traditional institutional designs that grant bounded and subordinate powers to local governments, as part of a sovereigntist model focused on the nation-state. With globalization this scheme has changed, and now local governments in large cities take on new powers that correspond to the emergence of metro nodes linked to global markets, and to the dynamic reconfiguration of economic, political, social and demographic flows. This connection takes place through networks of cities and the integration of regions that feature asymmetrical concentrations of resources and power, thus changing the map of te $\neg$ rritorial development.

KEYWORDS | local governments, globalization, public policies.

Recibido el 29 de mayo de 2013, aprobado el 22 de octubre de 2013

E-mail: edgar.varelabarrios@institutoprospectiva.org

Correspondencia: Instituto de Prospectiva, Innovación y Gestión del Conocimiento, Universidad del Valle, Sede San Fernando. Calle 4B N 36-00, edificio 126, oficina 3001, Santiago de Cali, Colombia 


\section{Introducción}

Este artículo analiza las transformaciones que ha sufrido la implementación de políticas públicas ${ }^{1}$ a cargo de los gobiernos locales, en particular en las grandes ciudades y sus áreas metropolitanas, transformaciones producidas principalmente-aunque no de forma exclusiva- por los cambios en los paradigmas de gobernabilidad de los territorios y las ciudades (cfr.: Banco Mundial, 2009; Borja \& Castells, 1998; Glaeser, 2011; Jewson \& MacGregor, 1997; Sassen, 1999, 2010; Ziccardi, 2008, 1996). Estos espacios, desde hace varias décadas, transitan desde una oferta de servicios y un amplio campo de cobertura por parte de burocracias públicas, en condiciones de monopolio y asignación no mercantil de bienes públicos y sociales, hacia un esquema abierto, diversificado, aupado por procesos de liberalización, con numerosas áreas de privatización y desmonopolización. En los últimos cuarenta años, la revolución de las telecomunicaciones, el globalismo, la apertura de las fronteras, las transformaciones de las soberanías de países y territorios, y la interdependencia creciente entre las grandes ciudades y las regiones metropolitanas en prácticamente todas las áreas y continentes, han transformado de forma sustancial las tradicionales funciones o competencias a cargo de los gobiernos locales (Varela, 2007a, 2007b; Veliz, 1999). Lo anterior, sin dejar de lado la continuidad profundizada de tendencias del desarrollo urbano, que han sido concomitantes al capitalismo en términos de larga duración. De allí que no sea posible vislumbrar el panorama emergente en términos simplistas y antitéticos, de un antes y un después, puesto que en él se manifiestan cambios significativos, a la par que se profundizan continuidades en procesos sociales, prácticas y políticas de gestión territorial.

Las relaciones y formas de gobernabilidad de los territorios metropolitanos en la operación y ejecución de políticas, resultan jalonadas por dinámicas de tipo económico y productivo que dominan la agenda de los gobiernos locales. Un tema de debate y cuestionamiento que se vislumbra es la determinación de las jerarquías en las políticas y en las agendas públicas de los territorios y áreas urbanas y metropolitanas. ¿Hasta qué punto la competitividad se logra en detrimento de la función residual o subalterna de la equidad y de la integración social? $\mathrm{O}$ ¡es evidente la correlación entre la prosperidad económica de las regiones ganadoras y la distribución de los ingresos, rentas y oportunidades?

Estas tensiones no son únicas o exclusivas de la relación entre competitividad y equidad, sino que se relacionan con la gobernabilidad, en términos del ejercicio de derechos, y con las demandas ciudadanas frente a los riesgos derivados de la inseguridad y la violencia urbanas. Son, estos últimos, fenómenos que cada día asuelan los territorios y las regiones metropolitanas, y que también afectan los fundamentos del desarrollo sostenible y los problemas de calidad de vida en los hábitats urbanos (Alzate, 2010; Banco Mundial, 2009). Por lo tanto, resulta clave vislumbrar cuáles de estas tendencias se han convertido en isomorfismos de la gestión territorial, sobre

1 Sobre el tema de la implementación existe una amplísima literatura. En el terreno general, véase: Bardach (1977); Pressman y Wildaslky (1973); Terpstra y Havinga (2001). Sobre la implementación por parte de los gobiernos territoriales, entre otros, cfr.: Borja y Castells (1998); Brugué y Gomá (1998); Castells (1976); Ziccardi (1996, 2008). 
todo en las grandes urbes. Recuérdese que, desde una visión clásica de las grandes urbes europeas, bajo el capitalismo, se las vislumbra como resultantes y catalizadoras del despegue industrial y de la concentración en centros de decisión políticoadministrativos de los mercados nacionales y de los Estados territoriales. Asimismo, las ciudades permitieron la absorción de las masas que migraban desde la ruralidad al mundo industrial y a los mercados urbanos, fenómeno que integró a las ciudades la descomposición del campesinado y escenificó el tránsito de su proletarización (Castells, 1976).

En las regiones periféricas del mundo y, en especial, en vastas áreas de América Latina-Colombia incluida-, se presentaron flujos acelerados de pobladores desde la ruralidad hacia las grandes urbes que se constituyeron, desde mediados del siglo xIX, como resultado de la industrialización endógena incipiente que a lo largo del siglo xx se consolidó y se complementó con la configuración de distritos industriales. En el caso colombiano, a este proceso se sumó el fenómeno de la violencia política, que exacerbó los flujos migratorios hacia las ciudades (Ibáńez \& Moya, 2007). Así, los cinturones de marginalidad muestran un modo específico de conformación de los tejidos urbanos, muy diferente del esquema clásico del capitalismo industrial. Prácticamente, estas zonas de marginalidad son comunes a los diversos países del continente americano, aunque con distintas denominaciones (favelas, tugurios, pueblos o ciudades jóvenes, etcétera). Estas dos vías antitéticas, capitalismo industrial y migraciones rurales, en buena medida, van a determinar capacidades institucionales, fiscales, administrativas, de governance, entre los modos de gestión de los territorios y las dimensiones contrapuestas de competitividad e inclusión social. Este asunto resulta clave, puesto que la gran concentración de riquezas, las rentas y las oportunidades de empleo, inversión y movilidad social, son altamente asimétricas en las grandes urbes. Pocas tienen un récord claro de mejorías sustanciales en términos de equidad y, en muchas de ellas, se ha dado un deterioro de las condiciones ambientales, de hábitat, infraestructura, vivienda y uso del espacio público como factor de sociabilidad (Canto, 2008; Ziccardi, 2008).

Para efectos de este artículo, se tomará en cuenta el caso de Santiago de Cali (capital del Departamento del Valle del Cauca, Colombia) y su área metropolitana, conformada por los municipios de Yumbo y Palmira (que limitan al norte) y Jamundí (que colinda por el sur de la ciudad), dado que desde mediados del siglo xx esta se ha venido desarrollando y consolidando mediante fenómenos inerciales de conurbación, consecuencia de dinámicas económicas, de infraestructura y habitacionales ${ }^{2}$.

\section{Estrategias metodológicas}

Para el análisis del desempeño de los gobiernos locales, se utilizó el método hipotético deductivo que, bajo el enfoque multi y transdisciplinario, resulta ser la estrategia más adecuada desde la perspectiva de las políticas públicas, ya que permite

2 Cali y su área metropolitana, según proyecciones del Departamento Administrativo Nacional de Estadística (DANE), al 2013 concentra 2.866 .096 habitantes, que equivalen al 63,4\% de la población del Departamento del Valle del Cauca (4.520.166 habitantes), en una superficie de $2.869,89 \mathrm{~km}^{2}$, que representa aproximadamente el $13 \%$ del territorio departamental $\left(22.140 \mathrm{~km}^{2}\right)$. 
articular, incluir y converger la literatura proveniente desde otras disciplinas, primordialmente desde la arquitectura y los estudios urbanos, sobre la base de categorías definidas en términos de la espacialidad, la geografía social y económica. Existe una amplia literatura de estudio e investigación pertinente que, aunque no sustituye el análisis de la política pública, resulta indispensable para el estudio y reconfiguración de las políticas territoriales en las regiones metropolitanas (Banco Mundial, 2009). La economía política de la competitividad y del desarrollo regional también ilustra las transformaciones de la vida urbana y las vinculaciones entre estos entornos metropolitanos y los procesos de transnacionalización, en relación con los grupos económicos, sociales y políticos a escalas macrorregionales.

Tómese en tal sentido como elemento clasificatorio la siguiente tipología:

- Los gobiernos locales de las grandes urbes, que involucran el desafío de la coordinación de políticas de varias autoridades locales en un área metropolitana, o -aunque no es un caso dominante- el de la compleja administración pública centrada en una gran ciudad, con un esquema unificado y relativamente centralizado.

- Los gobiernos locales de las llamadas ciudades intermedias, generalmente inferiores al millón de habitantes, pero superiores a los 150.000 o 200.000, y cuya acción, particularmente en países con elevados niveles de desarrollo, involucra la gestión de políticas públicas por parte de administraciones municipales, con un amplio margen de captación de recursos fiscales y con la posibilidad de incluir la coordinación de actores de nivel provincial, o subnacional, y también de las agencias del orden central o nacional.

- Los gobiernos locales en las pequeñas municipalidades que, en general, se ubican como ejes de áreas rurales con economías campesinas y con lógicas autárquicas externas a las dinámicas de los mercados globalizados. Cabe advertir que, en los países desarrollados, muchas de estas pequeñas municipalidades han tenido la capacidad de recaudar recursos fiscales, los cuales permiten la operación de políticas con un cierto rango de autonomía y discrecionalidad, y establecer esquemas locales de rendición de cuentas. En cambio, en los países en vía de desarrollo, las municipalidades pequeñas carecen de autonomía fiscal, su capacidad de recaudamiento es limitada y por ello son altamente sensibles a los esquemas de transferencias intergubernamentales, provenientes de niveles intermedios (gobernaciones o provincias) o principalmente del nivel central. Muchas de las políticas públicas, imputables a los gobiernos locales, son acciones de cabildeo y de intermediación con las autoridades centrales y regionales, que poseen tanto el poder político como la soberanía territorial y fiscal que les permiten la asignación de los recursos y las posibilidades de responder a las demandas ciudadanas o a la ejecución de los planes de desarrollo que se establezcan a nivel local.

Teniendo en cuenta la anterior clasificación, el presente artículo focalizará el análisis en el tipo de gobiernos locales de las grandes urbes, a partir del caso de Cali y su área metropolitana. Desde el punto de vista de las estrategias metodológicas, se ha utilizado la técnica de análisis documental, tomando en cuenta ciertos estudios de casos 
como fuentes primarias institucionales e incluyendo varios procesos de intervención a nivel de estudios de asesoría, consultoría y construcción de agendas publicas regionales en varias ciudades colombianas; entre ellas, Bogotá, Cali, Medellín, Pereira, Cartagena y Barranquilla (Brand, 2001; Martínez, 2005; Mertins, 2007; Pineda, 2009; Restrepo, 2007). En especial, se corroboran las nuevas relaciones que han emergido entre estos actores públicos y los Estados nacionales, así como las redes de articulación entre regiones más allá de las fronteras nacionales, y el peso de la inserción de las regiones, en tanto conjuntos de ciudades, en las economías y culturas globales. En tales procesos han participado múltiples actores, desde los propios gobiernos a los gremios económicos y el llamado sector productivo, las universidades y centros de investigación, así como, en distintos grados, esferas de las comunidades y de la llamada sociedad civil (Gobernación del Valle del Cauca - Centro Nacional de Productividad, 2010; Medina, Gutiérrez \& Gómez, 2009).

Existe también en esta estrategia metodológica un importante componente etnográfico. El autor ha participado de manera directa en este tipo de procesos en Cali y su entorno regional, el Departamento del Valle del Cauca (Varela, 2005; Varela, Escobar \& Escobar, 2009; Varela, Tabarquino, Delgado \& Martínez, 2009). En la ciudad de Cali, además, se han desarrollado otras iniciativas de planificación del desarrollo regional, como el "Cali Visión 2036" (Medina et al., 2009) y el "Plan Maestro de Desarrollo Social, Prospectivo y Sostenible del Valle del Cauca" (Gobernación del Valle del Cauca, 2003), así como la construcción al año 2036 de la "Agenda Regional de Competitividad con Equidad", en la que el autor actúa como coordinador, con participación activa de los congresistas de la región, otras universidades, los gobiernos territoriales y el sector empresarial del departamento (Universidad del Valle, 2012).

Igualmente se realizó la revisión de literatura relacionada con los temas de desarrollo regional, políticas públicas, globalismo, gobernabilidad y gobernanza como fuentes secundarias útiles para la construcción de los marcos referenciales e interpretativos de los roles de los gobiernos locales en el marco de la globalización y de las dinámicas del desarrollo regional.

De otro lado, el enfoque utilizado aquí va más allá de la noción del ciclo de política, pues considera la productividad y la genealogía de la política pública en términos de redes, articulaciones e interrelaciones sistémicas, con elementos de continuidad estructurantes y que, por lo tanto, sirven de base en muchas dimensiones de variabilidad. En este sentido, se toma en cuenta que las ciudades globales y las regiones metropolitanas son altamente sensibles a las transformaciones de la economía, la vida social y la geopolítica. Esto se explica porque ellas per se no tienen un lugar predeterminado, sino que dependen en su gestión exitosa de la capacidad de lectura de estos cambios y transformaciones para fundamentar políticas de adaptación, innovación y aprovechamiento de las ventajas comparativas y competitivas. Las formas, competencias y capacidades de los gobiernos locales para ejecutar políticas, no son abstractas e intemporales. En particular, son bastante grandes las diferencias entre las regiones metropolitanas (Borja \& Castells, 1998; Castells, 1976; Sellers \& Hoffmann, 2008) y el rol de los gobiernos locales en los países de desarrollo industrial avanzado, frente a los mismos desafíos en regiones metropolitanas 
del antes llamado "tercer mundo", aunque algunos temas y desafíos son comunes, al menos parcialmente. Así, la seguridad urbana, la marginalidad social y la exclusión, el urbanismo y el hábitat, los problemas de infraestructura y de movilidad e interconectividad en estas áreas densas, se podrían analizar en dimensiones convergentes.

\section{Los gobiernos locales y sus competencias operativas clásicas en el Welfare State}

La gobernabilidad política de los territorios ha sido vista en la literatura moderna, en especial desde las ciencias políticas y de la gestión, como la capacidad efectiva de los Estados para diseńar y ejecutar políticas públicas en el territorio de sus jurisdicciones, enfocándose en las poblaciones impactadas por estas, sea en una perspectiva moral -beneficiarias o receptoras de las políticas- o en una perspectiva conflictual, como demandantes de políticas (muchas veces acompañadas de grandes tensiones) que se le reclaman al nivel central del Estado. En general, se trata del predominio o la hegemonía de visiones Estado-céntricas, tanto de las políticas como de la propia gobernabilidad territorial. Esto obedece ciertamente a un papel debilitado o subordinado de los territorios subnacionales y de los gobiernos locales, dado que el rol tradicional de los municipios y los gobiernos locales era relativamente simple, con las competencias más importantes y cruciales asignadas, en tales modelos soberanistas, al Estado central. En efecto, se les prohibió a los territorios ejercer funciones de diplomacia o relaciones internacionales de cooperación. Cualquier contrato, convenio o endeudamiento debía avalarse y garantizarse por el nivel central, y así muchos ámbitos de la soberanía subnacional les fueron decomisados a los territorios.

Una serie de reformas y modelos constitucionales les dieron el centro de las decisiones de la vida pública a los gobiernos nacionales, a los parlamentos y a las autoridades jurisdiccionales del nivel central. De esta manera, la dimensión de políticas públicas a cargo de los gobiernos locales fue de naturaleza complementaria y, en algunos casos, muy prototípicamente acotada a asuntos de la vida cotidiana. Estos incluían materias que afectaban ciertas interrelaciones sociales, pero que no definían la dotación de los bienes y servicios públicos más significativos para los ciudadanos en áreas residenciales, y para el sector empresarial y las organizaciones e instituciones de diverso tenor que requerían ciertas reglas, como por ejemplo, sobre ordenamientos del uso del suelo o sobre la fiscalidad en términos de ventajas comparativas por parte de los gobiernos locales.

Recuérdese, complementariamente a este primer punto, que los gobiernos locales son definidos generalmente como estructuras y agencias administrativas de gestión de los territorios de las municipalidades, distritos y departamentos o provincias. Desde estas estructuras organizacionales y desde ciertos diseños institucionales surgen modos de implementación de políticas públicas, primordialmente en función de las competencias operacionales que les son asignadas por el Estado central. Esta definición no excluye una gran diversidad en las formas y tipologías, tanto en la espacialidad como en las competencias, recursos y ámbitos del ejercicio del poder público por parte de dichos gobiernos. En diversos grados, desde un mínimo de autonomía en los modelos centralistas, hasta un esquema más abierto 
en los federalismos, los gobiernos locales se definen ontológicamente por un nivel de base que fundamenta su soberanía en el ejercicio de sus competencias y en las relaciones políticas con la ciudadanía.

La espacialidad en la que se inscribe lo "local" es otro tema de amplio debate, con un uso abierto de tal categoría. El enfoque respectivo va desde la mirada que se sujeta a las restricciones definidas por los límites políticos y administrativos de las municipalidades, hasta una perspectiva más amplia que toma en cuenta las conexiones espaciales, las redes y los nodos urbanos y territoriales, tanto aquellos derivados de contigüidades espaciales y procesos de conurbación, como los que resultan de las dinámicas económicas, migratorias y culturales. Desde luego que estos fenómenos, aunque determinan en términos generales el despliegue de las capacidades institucionales de los gobiernos locales, no son ajenos a la enorme diversidad de estas tipologías. A pesar del auge formidable del urbanismo y de la concentración urbana en grandes megalópolis, aún sigue siendo muy fuerte el rol de otros niveles y formas de gestión. Como se recordará, la consolidación del modelo burocrático de gestión urbana, particularmente en las grandes urbes europeas, norteamericanas y poco después en las grandes ciudades de América Latina, África y Asia, se concentró en dos funciones principales: la planificación y organización del territorio, y la administración pública de los grandes centros urbanos.

a. La primera, la planificación y organización del territorio por urbanistas, arquitectos y expertos en desarrollo urbano. Desde gobiernos anteriores al siglo xx, se incorporó una dimensión central de la gobernabilidad local de los territorios: la planificación y el ordenamiento de los mismos a través de planes de renovación de áreas urbanas, cuyos epítomes más significativos se pueden encontrar en la ciudades de Nueva York del siglo xix y París de finales del siglo xviı y principios del XIX, aunque también son antecedentes importantes la planificación urbana de carácter imperial en las grandes capitales metropolitanas como Madrid y Lisboa, y -ya en el siglo xx-Santiago de Chile y Bogotá (Beuf, 2012), entre otras.

En el siglo xx, el desarrollo urbano partía de la nociones de segmentación, especialización, complementariedad y articulación de las diferentes áreas, distinguiéndose, en primer lugar, las zonas comerciales o centros administrativos, que constituían el nodo a partir del cual se dimanaba una radialidad residencial; y, más allá, asentamientos industriales, que en una primera etapa se encontraron entremezclados con los antiguos ejes metropolitanos, pero luego se deslocalizaron -en función de sus costos, particularmente del suelo, y de la contaminación producto de sus operaciones-, para ubicarse en zonas suburbanas, más exactamente en distritos industriales periféricos.

b. De otro lado, la administración pública de los grandes centros urbanos se encargó progresivamente de la oferta estatal de los servicios públicos. Se entendía por ello la gestión de la viabilidad de las infraestructuras urbanas a través de cuantiosas inversiones; principalmente, del trazado de las autopistas urbanas, con la definición de planes complejos de conectividad, incluidos sistemas de metro y trenes periféricos, que se amplificaron en gran medida cuando hacia principios del siglo xx se extendió el uso de los automóviles y los vehículos automotores. 
También se destacan los esfuerzos en la dotación de los servicios de agua potable, redes de alcantarillado, recolección de basuras, comunicaciones gráficas, suministro de fuentes y redes de flujo eléctrico, gas y telefonía, instalaciones y cobertura en salud, redes hospitalarias, sistemas educativos escolares y universitarios; y, por supuesto, en las ciudades capitales y grandes países, la conformación de la figura de la administración pública. Además, las burocracias públicas urbanas se configuraron en términos de la relación compleja, a veces dicotómica, entre ciudadanía, régimen local electoral de dichos gobiernos en formas diversas, versus la profesionalización y la burocratización de estirpe weberiana (García, 1974; Mouzelis, 1991; Peters, 1999). Esta administración pública civil ofertó los servicios y las políticas sociales más demandadas: salubridad, hábitat y vivienda, educación, integración o rehabilitación social, etcétera.

Sin embargo, pese a la consolidación del modelo burocrático de gestión urbana materializado en las dos funciones descritas, el crecimiento poblacional descontrolado en la mayor parte de las urbes de América Latina, Asia y África, generó enormes desafíos, retrasos y, en numerosas ocasiones, escenificó la incapacidad de los gobiernos locales para satisfacer las demandas públicas. Ello se debió, en particular, a las insuficiencias fiscales para atender las demandas que las ciudades hacían a las administraciones públicas, propulsadas por los negocios inmobiliarios y las dinámicas migratorias de carácter global y nacional. También fue notoria la falta de capacidades institucionales y operativas en términos de respuestas del aparato administrativo público, en especial desde que se profundizó la reconfiguración de los mercados nacionales, que incluyó las llamadas "ciudades globales" y la fuerza de atracción ejercida por la migración trasnacional. Estos retos superaron las capacidades de los gobiernos locales y exigieron intervenciones de políticas a cargo del poder central, para contrarrestar la insuficiencia de competencias en términos capacidad fiscal e institucional en las ciudades.

\section{Los impactos de la globalización y la liberalización de las sociedades y los mercados}

Las ciudades han sido, en la modernidad, escenarios clave para la construcción de las democracias liberales y para la puesta en escena de espacios de la vida pública, la deliberación, las sociabilidades y las interacciones de diverso tipo, incluyendo la movilización y la propia protesta urbana. El gobierno local es, por su naturaleza, el más cercano a los ciudadanos: asume los retos de la cotidianidad; las demandas específicas de la ciudadanía en relación con el hábitat, la vivienda, la calidad, cobertura y espacialidad de los servicios públicos; la propia oferta de la educación y, por supuesto, también los temas que, bajo el rubro genérico de "calidad de vida", incorporan las dimensiones de las industrias culturales, el entretenimiento, el ocio, la vida nocturna. Incluso, el espacio para la configuración de la propia criminalidad urbana se ha articulado en virtud de la oferta de ese tipo de mercancías y de los flujos de interacciones sociales. Tal como ha sido analizado recientemente, las ciudades son fuerzas centrípetas que tienen una enorme capacidad para atraer capitales y recursos, razón por la cual se potencian de manera asimétrica frente a las regiones rurales, 
periféricas y excéntricas en términos fiscales; y a la vez, las grandes urbes constituyen importantes fuerzas propulsoras del desarrollo económico (Sassen, 2007).

Desde esta perspectiva, las claves invariantes del desarrollo urbano son las siguientes:

a. Relación entre poblaciones, territorios y economía. Este tema ha sido enriquecido por el enfoque foucaultiano (Foucault, 2004), que definió el liberalismo político en términos de la gobernabilidad de poblaciones en marcos territoriales construidos con una institucionalidad pública liberal, la cual involucraba, como patrón central, las economías de mercado y el liberalismo económico, incluyendo la propia autonomía decisional de los sujetos. Esta gubernamentalidad se construía en términos de la policía o regulación que de los patrones sociales de convivencia territorial hace la administración pública.

b. Logística e infraestructura urbana. Como se expresó anteriormente, este ámbito de acción se constituye en uno de los principales de la acción gubernamental y territorial, aunque los Estados centrales y los gobiernos subnacionales tienen una importante responsabilidad respecto de las políticas sociales en ámbitos tales como los sistemas nacionales de salud y educación. Los temas de infraestructura constituyen, prácticamente en todos los países, una competencia y responsabilidad de los gobiernos locales. Los sistemas de transporte masivo, redes viales, hábitat, planificación del territorio y otras materias, aunque se basan en reglamentaciones producidas desde el nivel central, son el ámbito preferente y el espacio dominante de la legitimidad de las alcaldías, las administraciones públicas y los asentamientos urbanos (Orlansky, 1998).

c. En tercer lugar, de forma más reciente, la economía política de las ciudades ha implicado la asunción de un tercer ámbito de responsabilización politica por parte de los gobiernos locales. Al respecto, su papel en los mercados urbanísticos, oferta del hábitat, infraestructuras y construcción de vastas relaciones con el llamado sector terciario o de servicios dentro de las economías urbanas, resulta decisivo. En el periodo del globalismo neoliberal, estas actividades se han mercantilizado, desapareciendo muchos operadores públicos creados desde y por los gobiernos locales para atender este tipo de demandas, de tal manera que la gobernanza de las regiones metropolitanas define el papel de los gobiernos locales en términos de la coordinación de políticas.

d. Sobre la base de los anteriores elementos, se menciona cada vez más el papel crucial de los gobiernos locales en la coordinación de políticas, la articulación de múltiples actores para la planificación del desarrollo regional y territorial con miras a asegurar patrones y direccionamientos de larga duración, prospectivos, en función de las demandas de competitividad y la articulación de las ciudades globales en el contexto de los mercados trasnacionales.

e. Finalmente, los gobiernos locales deben asumir la garantía de los derechos humanos y el acceso a oportunidades bajo capacidad institucional. Este tema ha venido siendo enriquecido por Amartya Sen (2000), quien toma distancia de la noción de desarrollo fundamentada en el utilitarismo, la cual asume el crecimiento del producto interno bruto (РІв) y de la renta per cápita como elementos 
sustanciales del bienestar; y, por el contrario, se centra en lo que las personas pueden efectivamente hacer o ser con los bienes que poseen. En este sentido, los gobiernos locales deben -además de canalizar las demandas ciudadanascoordinar con los demás actores del desarrollo los mecanismos más idóneos para su satisfacción. Sen plantea que la capacidad de hacer o ser de las personas depende de las características de los bienes que posee, de sus rasgos personales y de la calidad de la estructura institucional que diseñe la sociedad, la cual deberá estar constituida por instituciones políticas y económicas que permitan un progresivo crecimiento económico, junto con una redistribución del ingreso; y por instituciones sociales con reglas claras e incentivos que fomenten la cooperación y la confianza entre actores que tienen preferencias e intereses divergentes para lograr fines colectivos (Varela, Martínez \& Delgado, 2013, pp. 212-213).

No se deben olvidar las limitaciones en las áreas o zonas de gobernabilidad propia por parte de los gobiernos locales frente a estos desafíos. En efecto, el papel de los gobiernos locales como promotores y ejecutores de la política, desde una visión clásica, se basó en diferenciar claramente las competencias del nivel central, sea el federativo en los países que tienen este tipo de poder público, o el poder delegado de naturaleza subordinada en los países o Estados nación con estructuras centralizadas de tipo unitario (Castells, 1983). En ambos casos, el asunto principal fue la delimitación de competencias a cargo de los gobiernos locales, desde una perspectiva subordinada o, en ámbitos concurrentes, precisando cuáles serían las competencias propias para los gobiernos locales.

En el caso colombiano, para el ejercicio de estos nuevos roles, los gobiernos locales enfrentan limitaciones relacionadas con el diseño institucional centralista que restringe la autonomía y gobernabilidad territorial; con la capacidad de gestionar y generar recursos fiscales para la implementación de políticas públicas en lo local; la capacidad institucional y gerencial para enfrentar las demandas de los actores en los territorios (Varela et al., 2013, p. 213); así como con el exacerbado individualismo del sujeto contemporáneo, que obstaculiza la deliberación política sobre los asuntos relacionados con el interés público y la construcción de ciudadanía, y con las debilidades en la cultura política, que se hacen más evidentes en algunas ciudades y regiones del país.

En las últimas décadas, las cosas han cambiado radicalmente. El posfordismo, el posindustrialismo y la globalización neoliberal, han transformado las relaciones entre el nivel central del Estado y los territorios (Banco Mundial, 2009; Glaeser, 2011; Sassen, 1999, 2010). Los gobiernos de las grandes ciudades y de las regiones metropolitanas más importantes del planeta asumieron competencias de facto y empezaron a desempeñar un nuevo papel que poco tuvo que ver con redefiniciones constitucionales; por el contrario, ellas resultaron de las dinámicas sociales, económicas y tecnológicas propias de la globalización, que empezaron a transformar y a romper la relación entre el centro y la periferia (entendiendo por centro las capitales de los países y por periferia los demás territorios), y a redefinir también las relaciones internacionales, generando una red de ciudades globales que acentuaron sus vínculos. Se atestigua la emergencia del modelo de "ciudades globales" y de ciudades-región 
(Sassen, 2003). Estas se estructuran frecuentemente en conurbados metropolitanos que incorporan vastas áreas con distritos industriales, para satisfacer las demandas del mercado interno y como plataformas de exportación, incluyendo las llamadas zonas franca o zonas económicas especiales. Tal ha sido el caso de Cali y su área metropolitana, que se gestó desde principios del siglo xx con la conexión ferroviaria entre el distrito industrial de Yumbo y el principal puerto sobre el Pacífico colombiano (Buenaventura), y se consolidó a partir de la segunda mitad del siglo xx, una vez finalizada la construcción del acceso vial ${ }^{3}$. Estas obras de infraestructura no solo fueron determinantes para el crecimiento y consolidación de Cali y su área metropolitana, sino que significaron la inserción de la economía colombiana -concentrada especialmente en Bogotá, Antioquia, Quindío y Valle del Cauca- en las principales rutas de comercio internacional de la época. Con posterioridad a estas dinámicas económicas y sociales, el Gobierno Nacional gradualmente fue formalizando dichos procesos a partir de la reforma constitucional de 1968, con la que se creó la figura de "áreas metropolitanas" en el país. A ella se sumó un conjunto de leyes (Ley 61 de 1979), decretos (como el Decreto-Ley 1333 de 1986), y reformas constitucionales posteriores (Ley 128 de 1994) a la expedición de la Constitución Política de 1991, que les asignaron un rol preponderante a los municipios como cofinanciadores e implementadores de políticas públicas (Carrión, 2009, pp. 220-222).

El cambio más fuerte que se ha producido con la globalización y la liberalización de los mercados en una escala planetaria, ha sido la reemergencia del poder político de los gobiernos locales y las autoridades territoriales subnacionales. Esto ha transformado el mapa correspondiente a la forma política de subordinación que caracterizó a los territorios o regiones frente al nivel central del Estado en el capitalismo clásico, industrialista. Con las reformas neoliberales y la apertura a la competitividad global, los Estados naciones se han debilitado, en términos generales, cediéndoles espacio a formas de regulación trasnacionales, a los mercados, y reeditando un rol renovado para las regiones, las ciudades regiones y las regiones metropolitanas (Evans \& Davies, 1999; Varela, 2007a). Estas instancias se articulan entre sí, establecen vínculos de todo tipo, sin que sea necesaria o determinante la mediación del Estado central. Este fenómeno ha propulsado en los distintos continentes y países el rol de regiones estratégicas de inserción global, particularmente el de aquellas que se ven a sí mismas como ganadoras o beneficiarias de los procesos de acumulación y reproducción de los capitales y los mercados en la competitividad global.

En este punto conviene hacer algunas consideraciones sobre las tendencias urbanas, poblacionales y las dinámicas de relacionamiento de lo rural y lo urbano. Téngase presente que el documento del Banco Mundial ya citado, Hacia una nueva geografía económica (2009), representa en cierta manera una ruptura de los paradigmas tradicionales sobre los asuntos de geografía económica, pues estos han

3 En esta última etapa se evidenció un proceso de urbanización acelerado que hizo que Cali pasara de tener 10.000 habitantes en 1810 , a 800.000 habitantes en 1960 y actualmente (2013) a contar con 2.319 .684 personas. Se trata de un crecimiento significativo para una zona que era prácticamente inexistente como eje regional y urbano del desarrollo del suroccidente colombiano, y que en menos de ochenta ańos emergió a lo largo del siglo pasado como nodo de una importante región metropolitana. 
intentado corregir las dinámicas mercantiles de concentración de población y de recursos económicos en las grandes urbes. Este informe considera que se debe trabajar sobre estas tendencias de concentración, considerándolas como inevitables e intentando generar políticas públicas que permitan mejorar el desarrollo económico a partir de transformaciones en las tres dimensiones que atraviesan como un hilo conductor el conjunto del estudio del Banco Mundial: densidad, distancia y división. Estos conceptos aparecen allí de manera correlativa y complementaria: la densidad, entendida como aglomeración y urbanismo; la distancia, entendida como la espacialidad que implica trabajar los factores de migraciones y desarrollo territorial, tanto de un país como del mundo entero, a través de circuitos económicos, sociales, culturales, etcétera; y en tercer lugar, la división, que implica la especialización y la integración regional. En este sentido, los gobiernos locales deben -además de canalizar las demandas ciudadanas- coordinar con los demás actores del desarrollo los mecanismos más idóneos para su satisfacción, lo que básicamente alude al tema de la soberanía, es decir, la existencia de territorios, cada uno con sus propias normas y jurisdicciones, para lo cual se propugna un abatimiento de los principios de soberanía, de manera que en su lugar operen integraciones económicas, con base en políticas públicas macrorregionales y mundiales.

Hace un par de décadas se popularizó en América Latina la noción de ciudadregión, la cual describía la tendencia centrípeta como un resultado prácticamente natural de los fenómenos de urbanismo, lo que supone una relación de subordinación y asimetría absoluta entre un gran eje metropolitano y su entorno territorial, en una perspectiva que hoy en día se usa de forma acrítica. Alternativamente, otros tipos de categorizaciones, tales como la de regiones metropolitanas, explican de una forma más flexible, abierta y variada, las articulaciones y relaciones que los geógrafos denominan escalares, entre un nodo metropolitano y el complejo tejido de relaciones con el hábitat de influencia territorial. No necesariamente la región metropolitana se configura de manera dominante, puesto que cada vez más estas distinciones absolutas resultan irrelevantes, dado que las formas de conectividad a través de las tecnologías de la información, de la infraestructura de movilidad por el territorio -tanto de las personas como de los bienes, servicios, lugares y espacios de consumo y producción-, han generado una mirada más diversa y flexible de este tipo de articulaciones; en particular, de las agrupaciones de ciudades y municipalidades que entrecruzan ámbitos rurales y urbanos.

En el marco descrito, se asiste a la repotenciación de las grandes áreas metropolitanas, que se vuelven enormes fuerzas de atracción que capturan el capital, los recursos humanos, los flujos migratorios, y que redefinen las vocaciones económicas y las dinámicas sociales de las zonas rurales. Así, se genera una situación de tensión para las ciudades de tamańo intermedio, las cuales, para sobrevivir, tienen que asumir sobrecostos relacionados con la movilidad, el acceso a servicios, la generación de fuentes de empleo, entre otros. Subrayemos de qué manera cambia radicalmente la relación entre los territorios y el urbanismo, dado que los municipios -sobre todo en las grandes ciudades y más allá de las formalidades institucionales o de las limitaciones del régimen de competencia establecido por marcos institucionales- empiezan a abrirse a las dinámicas de la globalización, construyendo agendas 
que, aunque desde el punto de vista legal son informales, terminan dotando a los gobiernos locales de estas grandes urbes de una nueva institucionalidad.

En las regiones metropolitanas de América Latina, las presiones, en términos de demandas de políticas públicas para los gobiernos territoriales, han sido formidables y en muchos casos han excedido sus capacidades institucionales, organizativas y fiscales. Ello primordialmente por la fuerza centrípeta de atracción de las metrópolis sobre los migrantes de pequeńos poblados y de regiones rurales que han disparado su crecimiento poblacional, el cual se encuentra -a diferencia de lo que ocurre en el Norte- lejos de detenerse o de llegar a su punto culminante. Esto implica la aparición de densos y enormes cinturones de hábitat precario e informal (favelas, pueblos jóvenes, villas, tugurios, etcétera), con demandas no satisfechas en infraestructuras relacionadas con el equipamiento urbano. La densidad de las grandes urbes en América Latina se encuentra en los topes más altos del planeta, modelo de urbanización que se critica por lo que comporta en cuanto a carencias en espacios públicos, zonas verdes y áreas de sostenibilidad ecológica y ambiental, y contaminación por los vehículos de transporte público y particular, que en especial han deteriorado las aguas y la calidad del aire. Además, estas formas de hábitat y la pobreza de sus pobladores, que conllevan situaciones graves en términos de acceso con equidad a los bienes públicos y sociales, significan la fermentación de espacios de criminalización de la vida social y la emergencia de redes de "capitalismo sombra" o criminal (Kaldor, 2001; Lock, 2003). En este sentido, se ha reforzado la reclamación por el rol de los gobiernos locales en la garantía de la seguridad ciudadana y en la disminución de la criminalidad y la violencia de distintos orígenes.

Los principales desafíos que enfrentan las ciudades latinoamericanas podrían expresarse en términos de las patologías derivadas de un crecimiento acelerado y del agotamiento de los viejos modelos de urbanización modernizante, los cuales se expresan en el terreno político en un déficit de gobernabilidad de los sistemas políticos clásicos territoriales sobre las propias regiones metropolitanas. No se trata solamente de que la dinámica del agrupamiento poblacional y los flujos complejos escapen al área de gobernabilidad de los gobiernos territoriales, alcaldías o departamentos. Ello podría ajustarse adaptando los esquemas de gobernabilidad, creando administraciones públicas con capacidad de integrar las administraciones municipales fragmentadas y creando, en suma, gobernabilidades metropolitanas. Sin embargo, aun cuando en muchos países se ha avanzado en estos temas, no se supera el problema estructural que subyace al déficit de gobernabilidad. Esto expresaría la incapacidad, desde lo político territorial o metropolitano, de gobernar y regular los flujos migratorios, las tendencias poblacionales, los cambios en los patrones culturales y actitudinales de las poblaciones, así como -mucho menoslas dinámicas propiamente económicas, tecnológicas y los procesos de transformación de la producción, el intercambio y el consumo. Tales desafíos aumentan en la medida en que muchas municipalidades y regiones metropolitanas sufren crisis fiscales estructurales, las cuales no se derivan exclusivamente de una incapacidad institucional. Son, más bien, efecto de la subordinación, desde el punto de vista de las políticas fiscales, en que se encuentran los territorios respecto de los niveles centrales del Estado, que ostentan preeminencia para la captura de la mayor parte 
de las rentas legítimas que en los sistemas impositivos se construyen para financiar el gasto público estatal (Medellín, 1994; Velásquez, 1995).

\section{¿Qué hacen hoy los gobiernos locales en la ejecución de políticas públicas?}

Las tareas y competencias de los gobiernos locales en la actualidad van más allá de los formatos o restricciones legales y constitucionales, pues han sido transformadas de forma sustancial por las dinámicas e impactos de la globalización y las interdependencias entre grandes áreas urbanas. La primera funcionalidad sobresaliente ahora es la de coordinación de políticas públicas con dinámicas de governance. También emergen otras funcionalidades y competencias en la competitividad, el mercadeo urbano, las asociaciones público-privado, negocios inmobiliarios, el capitalismo por proyectos en los que el gobierno local opera como inversor y socio, el desarrollo y la planificación de los territorios, y la gestión del conocimiento. Los territorios, a diferencia del modelo anterior, dejaron de ser los grandes operadores del grueso de las políticas públicas en los campos de su competencia, y han transitado hacia nuevos y grandes desafíos en materia de coordinación. Esto no implica la desaparición absoluta de sus funciones operativas y de implementación. En áreas como la de seguridad urbana, se ha propulsado mucho el tamaño de las administraciones públicas y los recursos de inversión, además de las propias infraestructuras; igualmente, el peso de las tecnoestructuras administrativas centrales sigue siendo considerable. En cambio, en otras áreas se ha presentado una fuerte retirada, aupada por privatizaciones y también por la autonomización empresarial de los operadores públicos.

La coordinación de actores en la operación de las políticas

Así, desde la función de ejecutar políticas vía burocracias gubernamentales -es decir, con funcionarios pagados y adscritos a secretarías e instituciones públicas- se ha pasado como tarea principal de los gobiernos locales a la coordinación de políticas. Las secretarías, las agencias públicas se han convertido en buena medida en coordinadoras de políticas... ¿Qué coordinan?... En primer lugar, la relación entre diversos niveles de lo público-estatal. Como no hay competencias delimitadas (al menos en el caso colombiano, y en muchas otras partes de América Latina), el Estado nacional sigue haciendo políticas. La alta administración local, el alto management urbano, dedica una parte muy importante de su tiempo administrativo a la coordinación público-público. Básicamente, a las interrelaciones entre las agendas del gobierno local y de los temas distritales o metropolitanos, en conjunción o en interlocución, no exenta de conflictos, con el nivel subnacional territorial intermedio (en el caso colombiano, los departamentos; en otros países, las provincias, regiones autonómicas o Estados federativos). Esto tiene que ver con las dinámicas horizontales y verticales en agendas de carácter sectorial. Por ejemplo, en el campo de la salubridad pública, puede tratarse de la movilidad de los recursos y las personas en esquemas territoriales extensos y difusos, en los cuales las ciudades metropolitanas son cruces de caminos donde el deslinde de competencia no es explícito ni siquiera en los países altamente maduros institucionalmente. Lo mismo en asuntos de la seguridad ciudadana y los derechos humanos. 
Un ejemplo de este tipo de coordinación entre actores públicos de nivel local lo constituye el proceso de asociación de municipios denominada G11 (por el número de municipios que la integran), que ha venido liderando Cali desde el año 2012. Los municipios que hacen parte de esta asociación -Santiago de Cali, Buenaventura (Distrito Especial), Candelaria, Dagua, Florida, Jamundí, La Cumbre, Palmira, Pradera, Vijes y Yumbo- han suscrito un convenio de cooperación interinstitucional para la armonización de los planes municipales de ordenamiento territorial y la formulación de un esquema regional de ordenamiento para los municipios. En este proceso, la Universidad del Valle, a través del Instituto de Prospectiva, Innovación y Gestión del Conocimiento (IPIGC), brinda asistencia técnica para la integración y coordinación de los planes municipales de ordenamiento territorial y acompañamiento a las oficinas y secretarías de planeación de los municipios para su implementación. En el marco de esta asociación, los municipios han venido trabajando en la construcción de un Contrato $\mathrm{Plan}^{4}$, que en Colombia es una figura jurídica que les permite a los municipios asociados gestionar la asignación de recursos del presupuesto nacional no condicionados para la ejecución de proyectos estratégicos relacionados con renovación urbana, planes viales, dotación de infraestructura y servicios básicos, etcétera. A su vez, esta integración permite que los municipios organizados en "bloques" puedan tener una mayor interlocución política con el nivel central de gobierno.

En segundo lugar, existe también un trabajo administrativo muy grande, pero no suficientemente esclarecido teóricamente, sobre la relación entre el gobierno local y los operadores empresariales públicos. Uno de los mitos que resultó falso es que, con el neoliberalismo, el Estado empresarial se iba a acabar. Empero, las grandes empresas del Estado actúan bajo la lógica del privatismo organizacional. Se desempeñan como empresas privadas, guiadas por el ánimo de la rentabilización y el lucro, y con un grado bastante alto de autonomía respecto a la relación Principal-Agente (MacCarthaigh, 2011; Ventriss, 2002). Por lo tanto, si las empresas públicas, bien sean de acciones, participación mixta o puramente estatales, tienen autonomía para hacer política pública local, los gobiernos locales, las secretarías, las agencias municipales, tienen que dedicar un tiempo significativo a coordinar estas políticas con los operadores empresariales públicos para tratar de hacer convergentes sus esfuerzos. Esta es, por tanto, una actividad compleja de coordinación de la política con los operadores empresariales públicos, del resorte directo e inmediato de la administración pública municipal, interpretada en términos de la relación Principal-Agente, y de operadores empresariales públicos que generalmente alcanzan la configuración de conglomerados económicos de corte nacional o transnacional que, en muchas ocasiones, se articulan con el sector privado en forma de asociaciones

4 El Contrato Plan que se enmarca en las leyes 1450 y 1454 de 2011, tiene como objeto lograr la concertación de esfuerzos estatales para la planeación integral del desarrollo territorial con visión de largo plazo, en concordancia con lo dispuesto en el artículo 339 de la Constitución Política de Colombia de 1991, permitiendo a las entidades u organismos del nivel nacional y a las Corporaciones Autónomas Regionales, suscribir Contratos Plan con las entidades u organismos del nivel territorial y los esquemas asociativos territoriales (Departamento Nacional de Planeación [DNP], 2010). 
público-privado (Varela, 2006), a través de outsourcing, alianzas estratégicas, o transformándose en sociedades por acciones.

Un ejemplo de coordinación entre el gobierno local y los operadores empresariales públicos se evidencia en las acciones que se han venido desarrollando en la ciudad de Cali para armonizar las estrategias empresariales de la principal empresa pública operadora de servicios públicos domiciliarios (EMCALI), con los objetivos estratégicos del Plan de Desarrollo Municipal. Cabe recordar que esta empresa fue intervenida durante doce años por el gobierno nacional a través de la Superintendencia de Servicios Públicos Domiciliarios, y en el año 2013 fue devuelta al gobierno municipal, con lo cual recuperó su gobernabilidad para la toma de decisiones estratégicas y como fuente de financiación (vía transferencia de recursos) para la promoción del desarrollo de Cali y su área metropolitana (Varela, 2008; Varela, Tabarquino, Delgado \& Martínez, 2009).

Un tercer nivel de coordinación se construye con el sector empresarial y con grandes conglomerados, muchos de ellos de "clase mundial", que desempeńan un papel importante en la formulación de planes estratégicos de desarrollo. Estos ámbitos no son de competencia exclusiva de las secretarías de planeación, sino de los conglomerados y grupos de interés provenientes del sector privado que piensan la región en términos de su inserción en la competitividad global y regional. En este sentido, la Cámara de Comercio de Cali ha creado la Agencia de Promoción de Inversión en el Pacífico Colombiano denominada Invest Pacific, la cual es una corporación sin ánimo de lucro de carácter público-privada, que nació a la vida jurídica en noviembre 10 de 2010, y que busca atraer nueva inversión nacional y extranjera directa al Valle del Cauca, mantener e incrementar la inversión ya instalada y propiciar un mejor clima para la inversión en la región. Invest Pacific se constituye, por tanto, en un interlocutor que cumple un rol de coordinación muy importante con los gremios del departamento del Valle del Cauca y facilita diálogos con inversionistas, lo cual se considera como una forma de privatización de las relaciones de cooperación internacional para el desarrollo de la región.

Un último nivel lo constituye la coordinación de políticas con el llamado "tercer sector", con organizaciones no gubernamentales (ONG), asociaciones civiles de distinto tipo que, bajo este esquema, ejecutan políticas públicas. Generalmente actúan como contratistas corporativos del Estado, participan de convocatorias públicas, licitaciones de diverso tipo y concesiones, particularmente en campos que tienen que ver con la política social y con la dotación de numerosos bienes públicos. Adicionalmente, en la coordinación de políticas públicas, existe un trabajo largo y diferenciado según sectores, con organizaciones no gubernamentales o con el sector no empresarial privado, que se expresa en términos de la sociedad civil, la cual contrata u opera bienes y servicios públicos. También se presentan procesos de coordinación de políticas públicas con las propias dinámicas de organización ciudadana, particularmente en respuesta a la interlocución participacionista, propia de las autoorganizaciones de distinto cariz, construidas en los territorios, en las comunidades, en las zonas marginadas y en las distintas esferas de la sociedad civil no empresarial.

En este contexto, emerge la tarea de administrar el entorno territorial con los demás municipios. El rasgo destacable es la transversalidad en la implementación 
de las políticas públicas. Este concepto alude a las relaciones entre actores y operadores que fracturan los antiguos esquemas de división funcional y sectorial de tareas y competencias de las agencias públicas. Las tipologías de corte funcional en ministerios, secretarías de despacho y agencias especializadas, tanto en el nivel central de los gobiernos como en sus ámbitos subnacionales o territoriales, se manifiestan incapaces de responder eficiente y eficazmente a las demandas sociales. Ello porque los problemas que abordan las políticas públicas no se dejan encasillar en moldes artificiales, derivados de patrones clásicos, propios de las burocracias industriales y administrativas.

\section{Las privatizaciones y su gestión desde lo público-estatal}

En estas delegaciones hacia las empresas, el sector privado, las ONG, etcétera, existe un fuerte trabajo que va más allá de la mera coordinación de acciones analizada en el punto anterior. En muchas grandes ciudades de Europa, Estados Unidos y América Latina, los gobiernos locales han desplegado sofisticados sistemas de evaluación y seguimiento de los desempeños de los operadores, así como del seguimiento -mediante baterías de indicadores- de metas y desafíos, y construyen y gestionan mecanismos de ajustes y retroalimentación. Lamentablemente, este sistema de gestión de las concesiones y de regulación de los mercados que ofertan bienes públicos y servicios de distinto tipo es bastante limitado en el contexto colombiano. Por ejemplo, muchas de estas regulaciones y controles le competen al nivel central del Estado. A través de comisiones regulatorias, superintendencias y otros entes, se ejercen dichas tareas de forma altamente centralizada, aunque desconcentrada funcionalmente. Es decir, el Estado actúa -o pretende actuar- a lo largo del territorio, sin darles espacio de decisión, concertación y control sobre la oferta adecuada de los bienes y servicios públicos a los gobiernos locales. Además, en muchos de estos casos, las funciones son rebasadas por el propio mercado, y la ciudadanía (o los usuarios/clientes) carece de defensas y garantías efectivas frente a las posiciones dominantes de los operadores empresariales.

\section{La implantación de la Nueva Gerencia Pública}

\section{(o New Public Management - NPM) por parte de los gobiernos locales}

La implementación de políticas públicas por operadores municipales, a cargo de los gobiernos locales, tiene como eje la construcción y puesta en escena de una serie de dispositivos administrativos, entre los cuales sobresalen la gestión por procesos, los mapas de procesos y una conjunción de políticas administrativas que rompen la tradicional estructura divisional y funcional, característica de la administración pública en sus formas burocráticas tradicionales. Esto ha implicado que la governance se configure primordialmente a partir de redes sistémicas en el contexto de las ciudades-región, las cuales tienen, en muchas ocasiones, la pretensión o la política explícita de convertirse en "ciudades globales". Con ello, la implementación de políticas públicas se convierte en un momento crucial para la configuración de plataformas institucionales, en términos de reglas del juego, de mecanismos y formas pactadas con cierta estabilidad de interlocución entre los múltiples actores antes denominados, con el fin de promover políticas de inserción global. 
Lo anterior ha apuntado a la configuración de estrategias consensuadas mediante planificación participativa, plasmadas en planes prospectivos de mediana y larga duración, a veinte o treinta años, en las cuales se incorporan los métodos de escenarios, así como las dinámicas de movilización social de actores y grupos de interés que usualmente requiere este tipo de políticas. El New Public Management (NPM) se ha concretado en la destrucción del rol de las burocracias y de la lucha por desmontar la presupestación inercial, extender modalidades de operación privatizadas o delegadas al tercer sector, la introducción de indicadores y una revisión sustancial de los métodos de profesionalizacion de la función pública (Cunill \& Ospina, 2003). Todo esto aunado a un uso intensivo de las tecnologías de la información y las comunicaciones (TIC) y de los dispositivos y arsenales de la sociedad de la información, primordialmente desde el impulso al e-government y el open government.

\section{El mercadeo de ciudades}

En los últimos veinte años se ha afianzado el mercadeo urbano con perspectivas nacionales, regionales y globales, denominado city-marketing, que, a la manera de estrategias de segunda línea sobre la base de las políticas o apuestas de largo plazo de planes prospectivos de posicionamiento de las ciudades, configura acciones de carácter específico y diferenciado en diversos campos de actuación, convergentes de lo público-estatal con distintos niveles de gestión de las esferas privadas. En el caso colombiano, ello se realiza a través de asociaciones gremiales sectoriales, creándose redes de negocios y redes de políticas cooperantes para atraer capitales, turismo temático, etcétera. Se genera así una imagen corporativa, en función de producir al país o a las ciudades (especialmente las grandes) como marca. Ello va de la mano -en alianzas público-privado- con el propio rol de agencias locales especializadas, fondos mixtos de promoción y capitalización, junto con poderosas empresas públicas en lo general y sectorial. Todas estas instancias, con el apoyo de consultores del mundo académico y de los propios operadores de políticas, sirven de base a planes prospectivos y de mercadeo de ciudad, orientados a configurar los términos de las políticas de reordenamiento urbano y generar impactos duraderos y significativos en relación con los procesos de metropolización o conurbación.

La orientación estratégica señalada implica que una de las tareas principales de los gobiernos locales es el impulso del proceso de city-marketing, el mercadeo urbano. Ahora bien, una amplia literatura sobre la marca país tiene que ver con temas específicos de mercadeo, como los productos o las marcas de origen, la identidad regional, el turismo temático patrimonial, que demandan una buena parte de la tensión del tiempo y del direccionamiento estratégico de los alcaldes, gobernaciones y autoridades locales y regionales. En muchas partes del país se han hecho intentos por hacer mercadeo en el tema urbanístico, desarrollando la ruta religiosa, por ejemplo, y en Boyacá y Santander con la ruta artesanal, para abrir paso a un nuevo tipo de turismo que recupera la visión sobre lo patrimonial.

En este sentido, durante las últimas dos décadas se viene presentando una competencia entre las grandes ciudades por ser sedes de importantes eventos de interés mundial. Así, la ciudad de Cali fue sede en el año 2013 para la realización de la reunión de presidentes de los países que firmaron la Alianza para el Pacífico, al igual 
que fue escenario para los World Games (que son los juegos no olímpicos). Asimismo, en el mes de febrero de 2014, en esta ciudad se realizó el Campeonato Mundial de Ciclismo de Pista. Estos, por tanto, son eventos planeados y diseñados por organizaciones y organismos multilaterales en los que las ciudades compiten entre sí y deben ajustarse a las reglas discrecionales que ellos fijan, y cumplir con las demandas que realizan en términos de adecuación y/o construcción de infraestructura, logística, seguridad, procesos de renovación urbana (en algunos casos), movilización y coordinación de actores, entre otros. Bajo estas condiciones, los gobiernos centrales y locales deben realizar mayores esfuerzos fiscales y de cabildeo político tanto para la asignación de la sede como para el desarrollo de las actividades en caso de ganarla. De los resultados de estos procesos depende en gran parte la mayor o menor visibilización mundial a nivel político, económico y empresarial, de los países y sus territorios.

\section{Las acciones de configuración de plataformas e infraestructuras} para la competitividad global

Otro frente importante que consume bastante tiempo a los gobiernos locales, dependiente de los anteriores, es el de las políticas de renovación y reordenamiento urbano, y en general los programas y proyectos de reinvención de las ciudades a partir de la ejecución de planes parciales y sectoriales, en los que interviene un trabajo especializado de diseño por urbanistas, ingenieros y arquitectos. Dichas iniciativas se enfocan tanto en revivir los tradicionales polígonos urbanos de los centros históricos, para darles una dimensión sostenible, como en configurar acciones y respuestas de política pública al fenómeno de la metropolización.

Las llamadas ciudades digitales, con una alta incorporación de sistemas de información geográfica, de movilidad, tienen la capacidad de inventariar en tiempo real los patrimonios, las infraestructuras, los consumos. Además, han reforzado en gran medida la capacidad predictivo-proactiva no solo de las administraciones públicas, sino también de las redes complejas y de los diferentes grupos de interés, donde las coaliciones confluyentes en la gobernanza se construyen para realizar el direccionamiento estratégico de las ciudades. Se trata de un nuevo tipo de democracia con participacionismo abierto e infinito, pero que en la práctica se centra en esquemas neocorporativos donde los centros académicos, las universidades, los centros de pensamiento estratégico, los gremios económicos, las asociaciones de profesionales, los grupos sectoriales con agendas específicas, entre otros, van reconstruyendo la agenda pública de las regiones o áreas metropolitanas. Dicho participacionismo no deja de generar fenómenos de exclusión, particularmente de migrantes y de la población menos calificada, sectores a los que se trata mediante una política asistencialista en términos de focalización del gasto y de eliminación incrementalista de la pobreza.

\section{Participación social y construcción de legitimidad: ciudadanía y gobernanza local}

En función de las ideologías del NPM, se formula como un imperativo en la implementación de políticas, la puesta en escena de mecanismos de rendición de cuentas (accountability), control social y participación ciudadana. En un espacio práctico, la participación en la ejecución de políticas ha llevado a formas muy diversas de tercerización de programas sociales, en ONG y entidades de representación y agrupamiento 
de las comunidades de base. Los principios de cooperación entre los territorios, el sector privado y las organizaciones de la sociedad civil, se fundamentan ahora en reglas de actuación al interior de organizaciones ad hoc y ex ante. La organización de las comunidades y de los grupos no se basa solo en el principio de adhesión (voluntad), sino también en el de reciprocidad (aceptación). Por ello, el mayor peso de la sociedad civil depende de su capacidad real de interlocución con los actores con mayor poder de decisión, destacándose entre ellos las administraciones públicas. Este tema es a menudo cuestionado por numerosas organizaciones de base y redes sociales que desconfían del poder público y de sus agendas mercantilistas y competitivas. De todas formas, hoy es visible el alto grado de relacionamiento entre los gobiernos locales y la ciudadanía, incluyendo esquemas de atención de corte asistencialista, extendidos a lo largo y ancho de América Latina (Varela, 2012). Se implementan, en consecuencia, estrategias de cooptación que se justifican en discursos compensatorios frente a las asimetrías derivadas de la liberalización de los mercados, pero que, a su turno, les dan un creciente poder a los gobiernos locales en el uso direccionado y asistencialista de los recursos públicos. Estos elementos confluyen en una administración pública que se privatiza y se inserta en dinámicas mercantiles a través de asociaciones público-privado, sobre la base de la construcción de una ingeniería de indicadores que miden y evalúan la capacidad de los gobiernos locales para hacer un seguimiento en tiempo real de ellos, con el fin de palpar las transformaciones, patologías y logros de la vida urbana.

Ejemplos de construcción de gobernanza local y ciudadanía son los procesos de planificación estratégica que se han adelantado en Cali y el Departamento del Valle del Cauca a lo largo de las últimas dos décadas ${ }^{5}$, los cuales se fundamentan teóricamente en la complementariedad entre las políticas públicas, la gestión pública, la prospectiva y el desarrollo regional. Metodológicamente, estos procesos incorporan en varias de sus etapas la participación proactiva de diferentes actores, la cual permite identificar las problemáticas relacionadas con el desarrollo y la equidad desde lo local, así como posibles propuestas de solución que son sistematizadas y complementadas por la academia y sugeridas a las autoridades gubernamentales locales y regionales para su inclusión en la agenda pública. Esta forma de planificación del desarrollo ha mejorado la legitimidad de los actores públicos locales y la inclusión en las agendas del sector privado y solidario. pectivo y Sostenible del Valle del Cauca al 2015 (2003), las agendas de competitividad de los municipios de Palmira y Buenaventura, la Visión Cali 2036 (2008-2009), y el actual proyecto Visión Valle del Cauca 2032, entre otros. Dado que la ciencia no es democrática, estos procesos requieren del conocimiento experto para sistematizar la información y poner en evidencia tendencias de mediano y largo plazo. No obstante, la implementación y continuidad de estos procesos en la región se han visto obstaculizadas por diversos factores relacionados con la capacidad fiscal de los territorios, la puesta en marcha de modelos de gestión innovadores que afectan la estabilidad institucional, la continuidad de las políticas públicas y la gobernabilidad, entre otros. 


\section{La gestión internacional de la cooperación y la asociatividad regional y global}

Finalmente, vale la pena subrayar la importante concentración de esfuerzos en los temas de cooperación internacional por parte de las autoridades locales y de las burocracias especializadas, tanto públicas como privadas o en redes de asociación público-privadas, para articularse a tendencias y procesos transnacionales. Otro tópico significativo ha sido la configuración de diversas redes de articulación y cooperación global entre los gobiernos locales, algunas propias del multilateralismo regional y urbano, que abarcan desde las asociaciones con cierta formalidad de ciudades, hasta las formas complejas de redes de ciudades globales. Muchas de tales redes, que definen apuestas prospectivas de carácter ambicioso basadas en modelos de desarrollo sustentable ${ }^{6}$, han promovido nuevos temas en la agenda de las políticas locales, como la necesidad de definir adecuadamente la arquitectura de los poderes multiniveles, superando el viejo modelo escalar o concéntrico.

\section{A manera de conclusión}

A pesar de los cambios profundos propios del globalismo neoliberal, los gobiernos locales siguen siendo actores centrales del desarrollo económico y social. En particular, cabe subrayar de qué manera los gobiernos de las grandes urbes han ganado terreno respecto del pasado en la gestión del desarrollo económico y su inserción en los esquemas de competitividad de los mercados regionales y globales. No obstante, este espacio no ha sido ganado como producto de alguna reforma constitucional o por cambios en las políticas públicas que les reasignen competencias del nivel central del Estado, sino por efecto de la globalización, ya que las dinámicas económicas han abatido las fronteras nacionales, han disminuido la soberanía de los Estados territoriales y han generado procesos de integración y articulación que permiten

\footnotetext{
Existe una larga tradición de asociatividad prohijada en especial por la Organización de Naciones Unidas (ONU) y sus programas de hábitat urbano. Por ejemplo, la asociación CLGU (Ciudades y Gobiernos Locales Unidos), fundada en el 2004, relacionada con diversas asociaciones nacionales, oNG, gobiernos, especialmente. Esta red emergió sobre la base del éxito del llamado modelo "Barcelona” de gestión local postmoderna. Véase sobre este tema, entre otros: Cardarello y Rodríguez (2007). También existen otras redes más focalizadas, tales como la "Red Latinoamericana por Ciudades Justas y Sustentables", las de "ciudades educadoras" u otras asociaciones ad hoc sobre temas de seguridad, salud pública, pobreza, etc. Otro ejemplo reciente lo constituye la red de ciudades de Espańa y América Latina, denominada Movimiento AERYc, esta "acoge a electos locales, altos profesionales y directivos de más de 70 gobiernos regionales y locales de América y Europa (...) la consolidación de AERYC como movimiento teórico y práctico es debida al mayor reconocimiento que tienen sus pilares estratégicos iniciales (...) los gobiernos locales creativos, que saben identificar los retos más sentidos por la ciudadanía y logran articular un proyecto estratégico compartido con los principales actores económicos y sociales, son capaces de hacer avanzar de manera estable las ciudades, aún en condiciones de entorno muy precarias, como es el caso de las ciudades colombianas y brasileñas (...). El segundo pilar consiste en el protagonismo creciente que se atribuye a las relaciones entre gobierno regional y gobiernos locales en la denominada sociedad del conocimiento o sociedad red (...) esta red entiende la gobernanza como (...) la capacidad de representación de la sociedad por parte del político electo, y que tiene como principal instrumento la gestión de las interdependencias e interacciones sociales" (Pascual \& Fernández, s.f.).
} 
que algunas ciudades tengan locus significativos con otras regiones y con los flujos centrales del capitalismo-mundo (Varela, 2007a).

Lo anterior ha implicado que la governance se configure primordialmente a partir de redes sistémicas, en el contexto de ciudades-región, que tienen en muchas ocasiones la pretensión o la política explícita de convertirse en "ciudades globales". Con ello, la implementación de políticas públicas se convierte en un momento crucial para la configuración de plataformas institucionales en términos de reglas del juego, de mecanismos y formas pactadas, con cierta estabilidad de interlocución entre los múltiples actores antes denominados, con el fin de promover políticas de inserción global. Esto generalmente ha apuntado a la configuración de estrategias consensuadas y trabajadas mediante procesos de planificación participativa, en términos de planes prospectivos de mediana y larga duración, generalmente, a veinte o treinta años plazo. A tal fin se han usado los métodos de escenarios, los esquemas de la planeación prospectiva con toda su tecnología, a la que se han sumado las dinámicas de movilización social y de actores y grupos de interés que usualmente requiere este tipo de políticas.

Adicionalmente, se ha generado lo que los profesores Luc Boltanski y Ève Chiapello (2002) han denominado, con lucidez, "capitalismo por proyectos". Se empiezan a vislumbrar grandes acciones de política pública, no como ámbitos que les correspondan a la Administración pública burocrática, o a planes y programas institucionales, sino como proyectos o megaproyectos empresariales. Allí se da una convergencia entre lo público y lo privado, en particular a través de la asociación de los Estados y sus empresas públicas con grandes inversionistas de carácter mundial. Se está dando igualmente, como base ontológica del capitalismo por proyectos, la mercantilización extendida de los bienes y servicios públicos. Desde hace poco más de cuarenta años, se está dando igualmente, como base ontológica del capitalismo por proyectos, la mercantilización extendida de los bienes y servicios públicos, donde las zonas de no mercado -que era la asignación de una serie de bienes públicos, como educación, salud, justicia, apartados administrativos, seguridad, diplomacia, etcétera- han pasado a ser parte de las zonas de mercado, propias del capitalismo y de la acumulación de rentas del capital. En este contexto, se mercantiliza el papel de las "ciudades globales", lo que afecta severamente las relaciones entre los gobiernos locales y sus territorios.

Ahora bien, la territorialidad está dominada por el nivel central en desmedro de las regiones y los gobiernos locales; es decir, se ha transfigurado. Ello ha impactado la dinámica económica y la producción; y, en cierta medida, sin darse ni una reforma constitucional ni un cambio de régimen político, ha modificado sustancialmente la relación entre el mundo urbano (sobre todo el de las grandes ciudades) y la territorialidad institucional. Las burocracias metropolitanas, generalmente inspiradas en el NPM, impulsan el desarrollo a partir de políticas fiscales en sus territorios, pero no lo hacen necesariamente bajo la anacrónica figura de los paraísos fiscales, es decir, la de atraer, mediante excenciones de impuestos, la inversión del gran capital. Más bien, operan fundamentalmente a partir de la implementación de políticas razonables de tributación que permiten que los gobiernos locales fortalezcan su soberanía fiscal, efectiva, suficiente y necesaria, para articular y movilizar recursos tanto privados, como del orden nacional (es decir, de los presupuestos estatales), de la cooperación 
internacional y de la propia movilización ciudadana, para dotar de infraestructuras económicas, políticas, sociales, culturales y organizacionales a sus territorios. Así, se potencia alcanzar la dimensión de ciudades globales, o al menos transitar hacia un posicionamiento adecuado de las administraciones públicas y de las ciudades-región en el contexto regional o subregional.

Tal como se observa, estas dinámicas impulsadas por la globalización se han puesto en evidencia a través del caso de la ciudad de Cali, en la que el gobierno local ha liderado procesos en los diferentes frentes de actuación en la vida social, política y económica de su área metropolitana, intentando ser congruente con los nuevos roles de los gobiernos locales que impone el actuar en un mundo globalizado. Para ello, ha tenido avances y retrocesos en su fortalecimiento institucional y en la gestión de sus entidades y corporaciones públicas, lo que ha afectado positiva y negativamente la coordinación de actores clave para la implementación de políticas públicas y la promoción del desarrollo en su territorio y su área metropolitana. Respecto a los procesos de privatización y gestión de lo público estatal, el Departamento del Valle del Cauca y el municipio de Santiago de Cali son de los territorios que más han avanzado a escala nacional en la agenda de privatización de empresas públicas (venta de acciones de la Sociedad Portuaria Regional de Buenaventura, Empresa de Servicios Varios [EMsiRva], empresas de servicios públicos en varios de sus municipios, privatización de la hacienda pública en Cali, etcétera), desmantelando así el Estado empresarial regional y afectando su capacidad fiscal para liderar procesos de desarrollo local y regional. Pero aunque se ha avanzado en la implementación del NPM, este no ha logrado consolidarse, dado que persisten lógicas patrimoniales, clientelares y burocráticas en la gestión de lo público en la región. Más aún, la implementación de este modelo no ha logrado resolver la provisión de bienes públicos con criterios de calidad, eficiencia y oportunidad, dadas las asimetrías regionales y de distribución del ingreso que caracterizan la región.

Finalmente, el municipio de Cali y su área metropolitana han mejorado en términos de construcción de infraestructuras y equipamientos urbanos relevantes para la competitividad, que han contribuido al mercadeo y visibilización de la región a nivel mundial.

\section{Referencias bibliográficas}

Alzate Z., M. L. (2010). Significado de las violencias locales en un mundo globalizado. Espacio Abierto, 19(3), 417-443. En http://www.redalyc.org/pdf/122/12215112004.pdf

Banco Mundial. (2009). Informe sobre el desarrollo mundial. Una nueva geografía económica. Panorama general, 2009. Washington, D.C.: Banco Internacional de Reconstrucción y Fomento/Banco Mundial.

Bardach, E. (1977). The implementation game. What happens after a bill became a law. Cambrdige, MA: MIT Press. 
Beuf, A. (2012). Concepción de centralidades urbanas y planeación del crecimiento urbano en la Bogotá de siglo xx. Ponencia en xii Coloquio Internacional de Geocrítica. Bogotá, Universidad Nacional de Colombia, 7 a 11 de mayo de 2012. En http://www.ub.edu/ geocrit/coloquio2012/actas/07-A-Beuf.pdf

Boltanski, L. \& Chiapello, È. (2002). El nuevo espiritu del capitalismo. Madrid: Akal.

Borja, J. \& Castells, M. (1998). Local y global: la gestión de las ciudades en la era de la información. Barcelona: Taurus Editores.

Brand, P. C. (2001). La construcción ambiental del bienestar urbano. Caso de Medellín, Colombia. Economía, Sociedad y Territorio, 3(9), 1-24. En http://www.redalyc.org/ articulo.oa?id=11100902

Brugué, Q. \& Gomá, R. (1998). Gobierno local: de la nacionalización al localismo y de la gerencialización a la repolitización. En Q. Brugué \& R. Gomá (Coords.), Gobiernos locales y politicas públicas. Bienestar social, promoción económica y territorio (pp. 16-35). Barcelona: Ariel, Ciencia Política.

Canto C., M. (2008). Gobernanza y participación ciudadana en las políticas públicas frente al reto del desarrollo. Revista Politica y Cultura, 30, 9-37. En http://www.redalyc.org/ articulo.oa?id=26711160002

Cardarello, A. \& Rodríguez, J. (2007). Las redes de ciudades como herramienta privilegiada para la gestión de cooperación descentralizada. Anuario de la Cooperación Descentralizada, 2. Montevideo: Observatorio de Cooperación Descentralizada Unión EuropeaAmérica Latina. En http://observ-ocd.org/sites/observ-ocd.org/files/publicacion/ docs/264_Anuario2_2.pdf

Carrión B., G. A. (2009). Los avatares de la institucionalidad metropolitana en Colombia: una breve revisión a la aplicación de la Ley 128 de 1994. Desafíos, 20, 217-252. En http:// revistas.urosario.edu.co/index.php/desafios/article/view/435

Castells, M. (1976). La cuestión urbana. Buenos Aires: Siglo xxi Editores.

Castells, M. (1983). The city and the grassroots: a ross-cultural theory of urban social movements. Londres: Edward Arnold.

Cunill G., N. \& Ospina B., S. (Eds.). (2003). Evaluación de resultados para una gestión pública moderna y democrática. Experiencias latino-americanas. Caracas: Centro Latinoamericano de Administración para el Desarrollo (CLAD).

Departamento Nacional de Planeación (DNP). (2011). Contratos Plan. En https://www.dnp. gov.co/Gobierno/ContratosPlan.aspx

Evans, M. \& Davies, J. (1999). Interpretación de la transferencia de políticas: una perspectiva multidisciplinaria y de niveles múltiples. Gestión y Política Pública, 8(2), 201-246.

Foucault, M. (2004). Sécurité, territoire, population. París: Gallimard-Seuil.

García P., M. (1974). Burocracia y tecnocracia. Madrid: Alianza Editores.

Glaeser, E. L. (2011). El triunfo de las ciudades: cómo nuestra mejor creación nos hace más ricos, más inteligentes, más ecológicos, más sanos y más felices. Barcelona: Editorial Taurus.

Gobernación del Valle del Cauca. (2003). Plan Maestro del Valle Regional, Integral, Prospectivo y Sostenible al 2015, Informe final. Santiago de Cali: Autor.

Gobernación del Valle del Cauca/Centro Nacional de Productividad. (2010). Diagnóstico del Estado del Arte de las dimensiones del desarrollo sostenible en el Valle del Cauca. Resumen Ejecutivo. Santiago de Cali: Centro Nacional de Productividad. 
Ibáńez, A. M. \& Moya, A. (2007). La población desplazada en Colombia: Examen de sus condiciones socioeconómicas y análisis de las politicas actuales. Bogotá: Departamento Nacional de Planeación.

Jewson, N. \& MacGregor, S. (Eds.). (1997). Transforming cities: Contested governance and new spatial divisions. Nueva York: Routledge.

Kaldor, M. (2001). Las nuevas guerras. Violencia organizada en la era global. Barcelona: Kriterios Tusquets Editores.

Lock, P. (2003). Transformaciones de la guerra: Hacia la dominación de la violencia reguladora. Cartagena: Foro Social Mundial.

MacCarthaigh, M. (2011). Managing state-owned enterprises in an age of crisis: an analysis of Irish experience. Policy Studies, 32(3), 215-230. doi: http://dx.doi.org/10.1080/0144 2872.2011.561688

Martínez T., P. M. (2005). La integración subregional y la caracterización funcional, morfológica del fenómeno de metropolización en el área de influencia metropolitana de Cali. Actas Latinoamericanas de Varsovia, 28, 67-92.

Medellín T., P. (1994). Democracia inacabada, transición o ficción democrática: los límites entre la reestructuración y el reformismo en América Latina. Nuevos itinerarios para un viejo problema. Papers, 44, 29-52. En http://www.raco.cat/index.php/Papers/ article/view/25235

Medina V., J., Gutiérrez G., I. C. \& Gómez, Á. (2009). Visión Cali 2036-Diagnóstico estratégico. Santiago de Cali: Alcaldía de Santiago de Cali/Universidad del Valle.

Mertins, G. (2007). Estudios urbanos-regionales desde el caribe: el crecimiento "moderno" espacial-urbano en Barranquilla: iplaneación pública-oficial o manejo del sector privado? Memorias-Revista Digital de Historia y Arqueología desde el Caribe, 4(007). En http://www.redalyc.org/articulo.oa?id=85540709

Mouzelis, N. (1991). Organización y burocracia. Madrid: Ediciones 62.

Orlansky, D. (1998). Las políticas públicas de descentralización. Revista Desarrollo Económico, 38(151), 827-844.

Pascual E., J. M. \& Fernández P., A. (Coords.). (s.f.). La gobernanza democrática: un nuevo enfoque para los grandes retos urbanos y regionales. Andalucía, España: Junta de Andalucía, Consejería de Gobernación.

Perters B., G. (1999). La política de la burocracia. México: Fondo de Cultura Económica/ Colegio Nacional de Ciencias Políticas y Administración Pública.

Peters B., G. (1999). La política de la burocracia. México: Colegio Nacional de Ciencias Políticas/Administración Pública-Fondo de Cultura Económica.

Pineda, D. S. (2009). Gobernanza territorial e integración regional en Colombia: la experiencia de Bogotá-Cundinamarca. En América-Europa de Regiones y Ciudades (AERYC), J. M. Pascual Esteve, A. Fernández Paricio \& J. Pascual Guiteras (Coords.), Los gobiernos locales en la construcción del futuro de los paises: Gobernanza urbana y desarrollo regional (pp. 101-125). Barcelona: Dirección General de Administración Local. En http:// www.aeryc.org/correspondencia/conclusions_03_2009/publicacion\%20caguas\%20 DEF\%20020608.pdf.

Pressman, J. \& Wildasky, A. (1973). Implementation how great expectations in Washington are dashed in Oakland. Berkeley, CA: University of California Press. 
Restrepo, C. I. (2007). Urbanismo social y desarrollo humano: la transformación de Medellín. Los gobiernos locales en la construcción del futuro de los paises: Gobernanza urbana y desarrollo regional (pp. 50-58). Barcelona: AERYC.

Sassen, S. (1999). The global city: New York, London, Tokyo. Princeton: Princeton University Press. [Edición en español: La ciudad global. Buenos Aires: Eudeba, 1999].

Sassen, S. (2003). Localizando ciudades en circuitos globales. EURE, 29(88), 5-27. http:// dx.doi.org/10.4067/S0250-71612003008800001

Sassen, S. (2007). El reposicionamiento de las ciudades y regiones urbanas en una economía global: ampliando las opciones de políticas y gobernanza. EURE, 33(100), 9-34. En http://repositorio.uc.cl/xmlui/handle/123456789/4084

Sassen, S. (2010). Territorios, autoridad, derechos: De los ensamblajes medievales a los ensamblajes globales. Buenos Aires: Katz Editores.

Sellers J. M. \& Hoffmann M., V. (2008). Metropolitan governance. United cities and local governments. En United Cites and Local Governments (Eds.), World Report on Decentralization and Local Democracy (pp. 255-279). Barcelona: United Cities and Local Governments.

Sen, A. (2000). Desarrollo y libertad. Buenos Aires: Editorial Planeta.

Terpstra, J. \& Havinga, T. (2001). Implementation between tradition and Management: Structuration and styles of implementation. Law \& Policy, 23(1), 95-116. doi: $10.1111 / 1467-9930.00104$

Universidad del Valle, varios autores. (2012). Agenda Regional de Competitividad con EquidadValle del Cauca 2036. Santiago de Cali: Secretaría Técnica al Bloque Regional y Parlamentario del Valle del Cauca.

Varela B., E. (2005). La mercantilización de lo público-Ensayos sobre gestión y politicas públicas. Santiago de Cali: Programa Editorial Facultad de Ciencias de la Administración.

Varela B., E. (2006). Visiones manageriales sobre el funcionariado público. La teoría de la burocracia revisitada. Serie Pliegos Administrativos y Financieros, 41. Santiago de Cali: Universidad del Valle, Programa Editorial Facultad de Ciencias de la Administración.

Varela B., E. (2007a). La soberanía transformada. Bogotá: ECOE Ediciones-Universidad del Valle.

Varela B., E. (2007b). Desafios del interés público-Identidades y diferencias entre lo público y lo privado. Segunda edición ampliada y mejorada. Santiago de Cali: Programa Editorial Universidad del Valle.

Varela B., E. (2008). Gestión y gobernabilidad en emcali. Liberalización de los servicios públicos y vulnerabilidad de las burocracias. Bogotá: ECOE Ediciones.

Varela B., E. (2012). La reinvención del asistencialismo participacionista: las politicas públicas de protección social en Colombia (1988-2012). Cartagena: Memorias XviI Congreso Internacional del CLAD sobre la Reforma del Estado y de la Administración Pública.

Varela B., E., Escobar Á., D. \& Escobar M., J. H. (2009). Los retos de la gestión pública en Cali: Eficiencia y modernización de la Administración Pública, rescate de la gobernabilidad financiera y recomposición de la soberanía institucional del gobierno local. En J. Medina, A. Pío \& I. Gutiérrez, Isabel (Eds.), Cali Visión 2036-Diagnóstico Estratégico (pp. 31-65). Santiago de Cali: Alcaldía de Santiago de Cali-Universidad del Valle.

Varela B., E., Martínez S., Á. M. \& Delgado M., W. (2013). Gobernanza y redes de políticas en el distrito portuario, industrial y biodiverso de Buenaventura, Colombia. Estudios Politicos, 43, 205-227. En http://www.redalyc.org/articulo.oa?id=16429828011 
Varela B., E., Tabarquino M., R. A., Delgado M., W. \& Martínez S., Á. M. (2009). Los servicios públicos en el municipio de Cali: condicionantes y catalizadores de su desarrollo urbano. En J. Medina, A. Pío \& I. Gutiérrez, Isabel (Eds.), Cali Visión 2036-Diagnóstico Estratégico (pp. 67-114). Santiago de Cali: Alcaldía de Santiago de Cali-Universidad del Valle.

Velásquez C., F. E. (1995). Descentralización y modernización del Estado en Colombia: balance de una experiencia. Nómadas, 3 (s/p). Bogotá: Universidad Central. En http:// www.redalyc.org/pdf/1051/105118914003.pdf

Veliz, P. (1999). Mundialización, ciudades y territorios. Barcelona: Editorial Ariel.

Ventriss, C. (2002). The rise of the entrepreneurial state governments in the United States: The dilemma of public governance in an era of globalization. Administrative Theory \& Praxis, 24(1), 81-102.

Ziccardi, A. (1996). La tarea de gobernar: las ciudades y la gobernabilidad. La tarea de gobernar: gobiernos locales y demandas ciudadanas. México: Porrúa Editores.

Ziccardi, A. (2008). Procesos de urbanización de la pobreza y nuevas formas de exclusión social: Los retos de las politicas sociales de las ciudades latinoamericanas del siglo xxi. Bogotá: Siglo del Hombre-Consejo Latinoamericano de Ciencias Sociales (ClaCso). 
